\title{
Under What Social Demand and Pressure Did the Existence of Sex Workers Rise From?
}

\author{
Guo $\mathrm{Yu}^{1, *}$ \\ ${ }^{1}$ University of California Berkeley, Berkeley, CA United States, 94709 \\ *Corresponding author. Email: alexyuguo2000@gmail.com
}

\begin{abstract}
Judge Posner has mentioned in the book Sex and Reason, that sex has been given economic and social meanings; however, some of those meanings remain controversial. Therefore, the primary research question in this paper is: under what social demand and/or social pressure did the existence of sex workers rise from? As we have probably known, sex worker, as one of the most ancient occupations, has long been associated with the social difficulties faced by women. Thus, this paper discusses the gender inequality, unequal sharing of social resources, and unbalanced social opportunities all together caused the formation of sex workers in our society.
\end{abstract}

Keywords: sex, gender inequality, $L G B T Q+$, social difficulties, prostitution

\section{INTRODUCTION}

There used to exist the sex workers in our society throughout the history; in fact, the sex worker is perhaps among one of the first-ever jobs that existed in the human society across all cultures. Although people's attitudes towards sex workers have changed throughout the years, it is still undeniable that sex workers have almost always been seen unfavorably in the eyes of the public, and while it is common to hear people grow up wanting to be lawyers, doctors, and scientists, little people grow up dreaming to become a sex worker. In addition, few people are born to be sex workers, therefore, becoming a sex worker is sometimes more likely to be a compromise one has to make due to various difficulties, instead of becoming one willingly.

To be able to help the sex workers out, researchers have to first further investigate what causes the challenges they have to face before having no option but becoming a sex worker. Hence, this paper primarily focuses on the question of "what drivers prostitution?" The conclusion of this research paper is that sexualitybased inequality in our society is the ultimate cause that leads to the existence of sex workers. One thing to note is that we will mostly limit our discussion within the more traditional, female sex workers due to their long existence in the history; however, there will also be a section to briefly discuss the newly emerged male and
LGBTQ+ sex workers towards the end of this research paper.

\section{HISTORICAL BACKGROUND}

Historically speaking, one of the most important reasons behind why sex workers have always existed could be explained by the simple economic concept of the demand and supply. Women could only be incented to become sex workers if there is a demand for sexual services. In 9.4 Prostitution, the article introduced how the prostitution, thus sex workers, emerged and developed. Prostitution is " as the world's oldest profession, prostitution has been common since ancient times". Prostitution is not only trans-generational, but also transcultural, which can be seen from the legalized and regulated prostitution industries in many modern-era, even developed countries such as Germany, Switzerland, Greece, Austria, and many other countries in Europe. "Red-light districts" in these countries remains one of the most popular attractions for locals and tourist. Countries that do not currently have legal prostitution also likely had long periods of prostitution in their history, not to mention all various forms of illegal prostitution that have been a huge headache for local police departments. In the U.S, for example, "prostitution was common in the United States through the nineteenth century" [1]. Many countries and cultures have had a long history of having 
prostitution, to a point where prostitution has been integrated to the culture and history so that it even impacted the fate of the country. For example, it might sound surreal but in fact prostitution played a significant role in the civil war. "During the Civil War, prostitutes found many customers among the soldiers of the Union and the Confederacy; the term hooker for prostitute comes from their relations with soldiers commanded by Union general Joseph Hooker" [2]. The desire for sex, just like other basic needs, if left unfulfilled, might cause various mental and health issues. Prostitution provided a way for the young soldiers to release their desire so that they were able to concentrate more on the war. Similar events happened during the WWI and WWII. One of the most famous examples was the existence of so-called "comfort girl," or "comfort women," which were consisted of sex slaves and prostitute, and treated as a special military occupation in the Imperial Japanese Army during the WWII. Aside from the wars, prostitution also has had profound impact in the literature. One of the most famous literatures in the Chinese history was Jin Ping Mei, as known as The Plum in the Golden Vase or The Golden Lotus, spends lots of efforts in trying to depict the stories happened in the brothels in Ming Dynasty, which was roughly a thousand years ago, so that we can have a clear picture of how it was like to be in the brothel. At the time, going to the brothel was seen as a luxury activity among the rich Chinese people because the sex service usually required lots of money, and visiting the brothel was even becoming a sign of money and power so that people always showed off doing so. Therefore, prostitution has had a long and profound history in the human history. With the understanding of the history of prostitution, let us now go back to our original question: "what drivers the existence of sex workers?"

\section{ANALYSIS ON THE REASONS OF BECOMING SEX WORKERS}

\subsection{Education}

The first reason, which is in my opinion also the most direct one, is the education; more specifically, the inequalities in the access to quality education between men and women. In the article, The History of Inequality in Education, the author explains how gender is an important category of inequality in the education system. The research paper provides us with ample examples and scientific evidences demonstrating the fact that there has indeed been a historical and present educational inequality between men and women. According to the historical events and timeline shown in the article, "higher education continued to be restricted to men in the early 1800s"'[3], so women were mainly uneducated before that, nor were they encouraged to do so due to the social expectation of women working as housewives, therefore no need to waste time getting educated: "In the colonial days, it was commonly accepted that women needed only to be prepared to be effective wives and mothers; consequently, their education was most often confined to emulating their mothers and obeying their fathers within the home."(Noltemeyer) Although people started to proposing the idea that "all individuals and groups should be treated with fairness, respect, and dignity and should be entitled to the resources, opportunities, and protections that schools offer" (Noltemeyer) under the American spirit of freedom after its dependence, women kept and continued facing educational inequality throughout history. Women were seen as supplements to their spouses, and were commonly expected to obey their husband and father. Only until the $1800 \mathrm{~s}$, "the first institution to offer baccalaureate degrees to women was the Georgia Female College founded in 1836," (Noltemeyer) and the "first state university to admit women did not emerge until the University of Iowa accepted women in 1855." (Noltemeyer) The education of girls, began to focus on increased literacy and skills beyond those needed to become good wives. As the result, women had little skills to keep a living if they urgently needed income in case of family emergency, or were abandoned by their family.

For example, it was common to see a poor girl's father got sick and urgently needed money to buy medicine to heal, and since the girl had no other skills to make money in the society, the only choice she had left was to trade her body for the money, because not only it was the fastest, the easiest, but also the only thing she did not have to learn to do so as an instinct. Another common example was that the wife was divorced by the husband, and she suddenly had no source of income. It was also hard for her to remarry as the result of the conservative idea towards women among men in the history, she was again, left with no choice but trading her body to support herself. In other words, the reason why women have been choosing to become sex workers is that sex worker as an occupation has the lowest barrier to entry. Being a sex worker does not require them to have years of education nor training, thus becoming one of a few jobs that are available to these women with low to non level of education. Furthermore, among all the jobs that do not require education, sex worker is perhaps the highestearned due to the correlation between having more money and easier access to sex among their male customers. Therefore, low education level is one of the fundamental driving forces behind women's choice to become sex workers. In fact, this still probably holds true for most of the prostitutes even until today. If you talk to the sex workers, it is not uncommon to find out that most of them have very little educational background, and it is also not uncommon to see their low level of education is 
due to their family's unequal invest in their education compared to their brothers.

\subsection{Employment problems}

The second reason for the existence of female sex workers would be the inequality in employment opportunities between men and women. This reason ties back to the education factor above, in the way that low education level results in few skills to be employed for, and low employment rate among women reinforces the systematic social perception of women's limited role as housewives. For example, in the 19th century, it was widely accepted that women were endowed with special qualities different from men, such as bearing and rearing children, and that it was their natural duty to stay at home to bear and raise children. Another way to approach this factor is through the inequalities women need to face in the workplace even after they are able to successfully land a job. For example, in the beginning when women started to work the same jobs as the male workers do, there was a fierce debate about whether women, especially married women, should be employed. The debate revolved around two fundamental questions: "should women be allowed to work after marriage," and "how about after being a mother," because people were worried that allowing married women and moms to work could not only decrease the efficiency to work due to their family occupations, but also result in fewer attentions and efforts women give to their families. In the article The Gender Gap in Employment: What's Holding Women Back, the author presents the gender gap in employment in terms of different expected gender roles in society, and the resulting reproduction of the gender gap due to the historically social stereotypes and norms, which result in involuntary unemployment among women. [4] In the modern era, although encouraging more and more women to get educated and become independent, they have to always face unequal treatments and pays compared to their male coworkers. As the worrying about the contradiction between work and marriage becomes prominent, some companies are even requiring women to sign the contract of promising to remain single in order for the female workers to be hired or promoted. The sad truth is that, these worries are all somewhat true. Based on the several research papers, interviews, as well as the discussion in online forums provided on the article, both women and men do agree that even until today, balancing the work and family responsibilities is one of the major challenges for them to perform well in the workplace, particularly for those married mothers, because compared to men, they have to spend especially more time to feed and raise the baby, and do most of the housekeeping jobs. Therefore, not only fewer job opportunities are available for women, but it also requires more effort for women to work the same job as men because they have more responsibilities and expectations imposed by the society. On the other hand, the effects of employment inequality are also disproportionately felt in divorced households. Since most of the time, the burden of child-rearing falls on the shoulder of divorced single mothers, it 's almost impossible to handle both parenting and high-pressure jobs. Hence, for those women who work for the lowwage and high-pressure jobs, becoming a sex worker is tempting due to its higher pay and lower work pressure, which also give them more time to take care of the family.

\subsection{Socioeconomic Status}

This factor was inspired by the concept of demand and supply of sex workers I have mentioned in the introduction. A man pays for sex workers' services simply because he has the demand for sex services, and such desire has not been seriously condemned by the society, if not encouraged like what we have seen in the history. Since in most societies women are still lower in socioeconomic status compared to men, it is much more socially acceptable for men to cheat on their wives instead of wives cheating on their husbands. In addition, when men are caught cheating on their wives by visiting the sex workers, they often face less social condemnations as well as the social punishments compared to women, therefore making the cost of cheating and going to the sex workers less than the benefit of the enjoyment they get from the sexual services, resulting in a huge demand for the sex workers if such situation is applicable enough to the majority of the societies. In addition, there is generally a positive correlation between the amount of wealth a man possesses and his likelihood to purchase the sexual services because sexual services are fundamental one of the many goods and services that can be purchased with money. A wealthier man is more likely to be able to afford such services, and due to the systematic gender inequalities mentioned in the education and employment sections above, men are more likely to become rich compared to women. Then another factor which drives the existence of the sex workers is from the demand side. Based on article 9.4 Prostitution, there are four major reasons and motivations for customers to find a prostitute: "the desire for certain physical appearance," " the lack of a sexual partner or dissatisfaction with a sexual partner," "the thrill of having sex just with a prostitute," and "the desire to have sex without having to make an emotional commitment." (9.4 Prostitution) Most of these needs arise within the rich people who have less time to maintain a long-term relationship while having lots of money to pay for their desired sexual services, therefore driving the price for sex workers high with their money. Why spend the time and energy to 
maintain a relationship if you can easily buy "happy" memories with money? The demand for sex worker's services reduced the efforts in personal interaction, and emphasized on the financial aspect of acquiring the sex. From the supply side, since "prioritizing money is the key feature to differentiate lover and sex worker,"[5] money is, without doubt, the major motivation for women to become prostitutes. In the book Sex and Reason, Judge Posner states that the social circumstances of gender hierarchies and discrimination lead to the market of sex workers [6]. The meaning of sex is determined by social power relations in society in which gender differences emerged. Therefore, the inequality in socioeconomic status is another fundamental factors that drives the existence of sex workers.

\subsection{Patriarchy}

The second to last factor we will be discussing in this research paper is in fact our historical patriarchy social system, and how it reinforces the socioeconomic factor we have mentioned in the above section. Due to the long history of the patriarchal social system, men has historically gained domination over women, and one of the most representative phenomena is the historical allowance of polygyny which even still exists in some regions today. Under polygyny, a man can have several wives while a woman can only have one husband; in other words, sex is also mainly controlled by men, and women are socially expected to be submissive to men, so sex work itself is also a symbol of male domination, and the materialization of women, because prostitution is basically women selling their bodies for money as they were selling some other goods. Men act as the buyer of women's bodies in the prostitution market, again showing their dominance over women. In the article What's Wrong with Prostitution? What's Right with Sex Work? Comparing Markets in Female Sexual Labor, the author articulates that "while the figure of the prostitute has served as a key trope in the writings and arguments of both groups - as symbolic of either the expropriation of female sexuality in general, or alternatively, of its socially subversive reappropriation - there has been surprisingly little empirical research done to investigate the lived conditions of contemporary prostitution" [7]. In addition, there have also been underlying questions of power, resistance, and the possibility of female sexual agency under patriarchy. It sounds cruel but sex workers are very comparable to the slaves, as they are both the product of social conformation and inequality; however, in my opinion, what makes sex worker even in worse situations than slaves is the fact that since almost all consumers of prostitution are men, so there is also gender inequality involved in sex work, in addition to slavery. "Prostitution is unique because it entails that the woman's (sexual) self be contracted out not just incidentally, but necessarily." (Elizabeth) Argues Pate man,"sale of women's bodies in the capitalist market involves sale of a self differently, and in a more profound sense, than sale of the body of a male baseball player or sale of command over the use of the labor [body] of a wage slave." (Elizabeth) In the article 9.4 Prostitution, the author also mentioned the similar idea towards the male domination, and stated that "prostitution results not only from women 's poverty but also from society's patriarchal culture that still views men as the dominant figure in heterosexual relationships and that still treats women as "sex objects" who exist for men's pleasure". (9.4 Prostitution) Therefore, the patriarchy social system and its resulting inequality between the power of men and women is also held responsible for the existence of sex workers.

\section{SPECIAL SUB-GROUPS OF SEX WORKERS--LGBTQ+ AND MALE SEX WORKERS}

So far we have only talked about the various causes that lead to the presence of female sex workers in our society from the perspectives of education, employment, socioeconomic status, and patriarchy, because for the most period of time in the history, the supply of sex workers have always been female, and the demand for sex workers have always been male. However, in the most recent decades, we have observed a gradual increasing in the demand for male sex workers, perhaps as the result of economic independence and higher socioeconomic status among women in the recent decades as the result of being able to access to the higher educations. What we have discussed as the probable causation to become sex workers for women are now more and more applicable to men as well for those who decide to enter the prostitution field and become a male sex worker. Aside from the male sex workers, LGBTQ+ communities, as a relatively new concept which are increasingly gaining the public's attention in the recent several decades as our society advances and enters a new era of freedom, just like how it allowed women to be educated in the higher education, are also getting gradually involved in the supply and demand side of the sex work. However, being a still disadvantaged sexual group, members of LGBTQ+ family often have to face even more challenges than the straight female and male sex workers do, including but not limited to the pressure from the family, friends, and society. They often need to worry about revealing their true identity in addition to other things such as lack of income and the need to support the family. Because of the discrimination against the LGBTQ community, many LGBTQ individuals have found no other way to maintain their life but to become a sex worker. Furthermore, sexual transmitted diseases such as AIDS and HIV are also scientifically proven to be easier to transmit within the LGBTQ+ communities, 
therefore there is also a higher risk of being infected working as a sex worker in these sub-groups. In the article Sex Work Is an LGBTQ Issue, the author said that "sex work has offered a lifeline for those marginalized, an opportunity for many with few, the backbones of nascent organizations and a sub-community for many who have been ignored by the respectability politics." (D'Adamo) The LGBTQ+ community has long faced the systematic discrimination and prejudices on top of the traditional gender inequality, which contributes to the higher participation rate in the sex work. "With discrimination in jobs, education and services, poverty has long been a queer issue. The trans community are twice as likely to be unemployed compared to cisgender individuals."[8] Thus, "LGBTQ-identified individuals have often relied on sex work as a means of survival." (D'Adamo) Therefore, although female sex workers are still the most populated, male and LGBTQ+ sex workers are becoming more and more common, and it is our society's responsibility to being successfully acknowledged and is aware of the even more severe inequalities these groups of people are facing, which push them to have no choice but become sex workers.

\section{CONCLUSION}

Therefore, what drives prostitution? From what we have concluded so far, the answer to this question is that sexuality-based inequality in our society is the fundamental driving force behind the prostitution and the existence of sex workers. Now as we have the answer and realizing the causation of such problematic social phenomenon, our ultimate goal is to explore ways to eliminate such issues in our society, otherwise only finding out the problem without solving it could never make our society a better place. As we have mentioned in the introduction section of this research paper, sex work, most of the time, is not a voluntary choice of individuals, but rather a compromise. Indeed, it is difficult to completely eliminate gender inequality and the demand for sex under our current society. In the article Social Construction and Identity from the textbook, the author states that "gender, sexuality, and even sex are cultural rather than biological categories." $[9,10]$ "It is much easier to be a racist if one believes there are natural race-based differences than if one believes that racial differences are artificial social constructions" [11]. Hence, the idea of gender and sexuality is not purely based on the biological level, but more on the cultural stereotypes and prejudice. This opinion is also evidently found in the article The Unspoken Horror of Incarcerated LGBT People, "sexual minorities are more likely to experience family rejection and community marginalization ... For women, powerful gender stereotypes are likely at play, to the extent that sexual minority women defy norms are labeled as aggressive or masculine, individuals or institutions may unfairly find them more deserving of punishment" [12].
Therefore, the secret code of combating the gender inequality in our society is hidden within our society itself. Gender inequality can exist everywhere in our society, and exist in everyone's mind, that is the exact reason why it is so challenging to overcome; however, it is also because the gender inequality exists everywhere in our society, and in the mind of me and you, if every one of us does our own parts right and starts changing our thoughts and behaviors, gender inequality would be easily combated, and the social issues associated with the sex workers will also be easily resolved. Further researches are still needed regarding how exactly we can change our thoughts and behaviors when dealing with existing gender inequalities in our society.

\section{ACKNOWLEDGMENTS}

While I'm working on my paper, I have received many heartwarming support and assistance from my Professor, Teachers, and family members. First and foremost, I would like to express my grateful feeling toward Professor Richard Ford, who introduced me to the field of equality law and inspired me to look upon social issue, such as gender inequality. Also, I would like to thank the teachers for their encouragement, insightful comments and proofreads. And lastly, I would like to extend my sincere thanks to my family member for always being there while I'm struggling.

\section{REFERENCES}

[1] "9.4 Prostitution." Social Problems, University of Minnesota Libraries Publishing Edition, Mar 25, 2016.

https://open.lib.umn.edu/socialproblems/chapter/94-prostitution/

[2] "9.4 Prostitution." Social Problems, University of Minnesota Libraries Publishing Edition, Mar 25, 2016.

https://open.lib.umn.edu/socialproblems/chapter/94-prostitution/

[3] Amity L. Noltemeyer, Julie Mujic,Caven S. McLoughlin, The History of Inequality in Education. [M] Sacred Heart University, 2012, pp319.

[4] International Labour Organization. The Gender Gap in Employment: What's Holding Women Back? Dec. 2017. www.ilo.org/infostories/enGB/Stories/Employment/barriers-women\#intro.

[5] William N Eskridge Jr, Nan D.Hunter, Sexuality, Gender, and the Law [M] Foundation Press, 2018.

[6] Richard A. Posner, Sex and Reason [M] Harvard University Press, 1994. 
[7] Elizabeth Bernstein, What's Wrong with Prostitution? What's Right with Sex Work? Comparing Markets in Female Sexual Labor [J] Hastings Women's Law Journal, vol. 10, no.1 20, 1999.

[8] K. D'Adamo, Sex Work is an LGBTQ Issue, 2018.https://survivorsagainstsesta.org/lgbtq/

[9] Judith Butler, Gender Trouble: Feminism and the Subversion of Identity [M] Routledge, 1999.

[10] Michel Foucault, The History of Sexuality [M] Random House Inc, 1978.

[11] Richard T. Ford, Racial Culture: A Critique [M] Princeton University Press, 2005.

[12] Lara Stemple, Ilan H.Meyer, The Unspoken Horror of Incarcerated LGBT People, Feb 23, 2017. https://www.advocate.com/commentary/2017/2/23/ unspoken-horror-incarcerated-lgbt-people 